\title{
Effects of Experience and Advice on Process and Performance in Negotiations
}

\author{
Wolfgang Steinel \\ Leiden University \\ Andrea E. Abele
Friedrich-Alexander University \\ Carsten K. W. De Dreu \\ University of Amsterdam
}

\begin{abstract}
This experiment ( $N=68$ dyads) tested the influence of experience and advice on behavior and joint outcomes in integrative two-party negotiations. Dyads in an advice condition received short tactical advice to question fixed-pie assumptions and to exchange information. Afterward, they negotiated once. Dyads in an experience condition negotiated twice in successive rounds. Finally, dyads in an experience-and-advice condition negotiated twice and received advice prior to the second negotiation. Dependent measures were negotiation behavior, negotiation duration, joint outcome, and judgmental accuracy. Results showed that the combination of advice and experience led dyads to apply more problem solving and fewer contentious strategies, which mediated the higher joint outcomes that these dyads reached in shorter times. Experience or advice alone was not sufficient to make negotiators use different strategies or to exploit the integrative potential of the negotiations better than they did before they received advice and/or gained experience.
\end{abstract}

KEYWORDS advice, contending, experience, fixed-pie perceptions, integrative negotiations, problem solving

In INTERNATIONAL diplomacy, in business, and sometimes even in intimate relationships, negotiation skills are the key to success. How negotiation skills affect success in these various domains has been a long-standing interest dating back to the works of Niccolo Machiavelli and Francois de Callières (e.g. Berridge, Keens-Soper, \& Otte, 2001). Nowadays, training and advice in negotiation is a million dollar business, with many writers offering best-selling books about negotiation (e.g. Fisher \& Ury, 1981; Ury, 1992) and many consulting firms offering courses in negotiation skills.

\section{Author's note}

Address correspondence to Wolfgang Steinel, Leiden University, Institute for Psychological Research, P.O. Box 9555, 2300 RB Leiden, The Netherlands [email: wsteinel@fsw.leidenuniv.nl] 
Whereas scholars like Francois de Callières were concerned primarily with ways to increase a negotiator's personal success, contemporary negotiation research and training recognizes that negotiator success is best defined in terms of the collective functionality of agreements (Bazerman, Curhan, Moore, \& Valley, 2000). Fisher and Ury's (1981) classic example of two sisters quarreling about an orange best illustrates this position: once the sisters decided to halve the orange, one squeezed her part to drink the juice, while the other used the peel from her part in a cake. Both sisters would have been better off if the first one had taken all the juice and the second one all the peel. Because most negotiations allow for such integrative agreements (Pruitt, 1981; Raiffa, 1982), why do negotiators persistently perceive negotiations as purely distributive (the so-called 'fixed-pie perception', Bazerman \& Neale, 1983)? Why do they so often fail to realize the integrative potential that can benefit everyone? This issue becomes all the more important once we realize that reaching integrative agreements fosters economic prosperity, strengthens feelings of selfefficacy, increases satisfaction, and reduces the likelihood of future conflict (De Dreu, Weingart, \& Kwon, 2000; Rubin, Pruitt, \& Kim, 1994).

Research probing the reasons for negotiators' failure to reach integrative agreements has focused on structural and motivational variables (De Dreu, Weingart et al., 2000; Druckman, 1994; Pruitt, 1981), on such cognitive barriers as memory deficits and erroneous reasoning (Bazerman \& Neale, 1983), and more recently on motivated information processing (De Dreu \& Carnevale, 2003; De Dreu, Koole, \& Steinel, 2000). Although such research has enhanced our knowledge of the barriers to constructive negotiations, it offers little advice about how to overcome these barriers. From a practitioner's point of view, a critical question is whether someone can actually learn to negotiate better, and whether such learning simply requires experience with many negotiations. Or maybe experience is not the critical issue, and becoming a successful negotiator requires the right advice instead. After all, research shows that expertise in a particular content domain does not necessarily derive from simply doing the same task over and over again (Sonnentag, 1998).

The question addressed in our research is whether experience, advice, or a combination of the two improves negotiation performance. We first review the literature on advice in decision making and a few empirical studies on the role of experience and advice in negotiator success. Unfortunately, the results of these studies are somewhat contradictory, and researchers have focused more on the outcomes of negotiation rather than the underlying behavioral processes. To fill this void, we report a face-to-face negotiation experiment in which specific hypotheses are tested about the (combined) influence of experience and advice not only on negotiation outcomes, but also on the underlying behavioral processes.

\section{Effects of advice}

Research on the use of advice in decision making (e.g. Harvey \& Fischer, 1997; Yaniv, 2004; Yaniv \& Kleinberger, 2000) suggests that people have a general tendency to egocentrically discount the advice they receive. Yaniv and Kleinberger, for example, asked their participants to make initial estimates of the years in which historical events took place. Participants then received advice in the form of other participants' estimates. Participants did combine their initial estimates with the advice they received, but gave final estimates that were much closer to their own initial estimates than to the other participant's estimates. This occurred even when the other participants were viewed as experts on the task. Yaniv and Kleinberger argued that decision makers discount an advisor's opinion because they are privy to the reasons supporting their own estimate, but not to the reasons supporting the advisor's estimates. Further evidence for the tendency to discount advice has also been reported (see Harvey \& Fischer, 1997; Harvey, Harries, \& Fischer, 2000; Lim \& O'Connor, 1995).

Fixed-pie perceptions are common at the onset of many negotiations, and revising these perceptions is related to more successful negotiation (Neale \& Bazerman, 1991; Thompson, 1991; 
Thompson \& Hastie, 1990). One goal of our research was therefore to uncover whether and when giving negotiators advice can attenuate such perceptions, or whether negotiators always discount such advice. Some researchers have found that giving negotiators advice and cues challenging fixed-pie perceptions influences their performance (e.g. Weingart, Hyder, \& Prietula, 1996). For example, Kemp and Smith (1994) informed negotiators that their own priorities might differ from those of their counterparts. This led to higher joint outcomes, compared to a control condition in which negotiators were not given this information about priorities (see also Thompson, 1991). However, several researchers have found that negotiators discounted similar advice and hardly revised their fixed-pie perceptions. For example, De Dreu, Koole et al. (2000) gave students information about an upcoming negotiation that included their own, but not their opponents' payoff schedules. The students' fixed-pie perceptions were then assessed. Later, the students received advice in the form of full information about their opponents' payoff schedules. After a short filler task, fixed-pie perceptions were measured again, and this time were weaker. This suggests that participants used the advice they received. Yet close inspection of the results reveals that even after receiving full information about their opponents' payoff schedules, participants rarely abandoned their initial erroneous perceptions. Similarly, Thompson and DeHarpport (1994) reported that in their research 'even some negotiators who were provided with full feedback about the other person's interests failed to report ... that their opponent had different priorities' (p. 341).

More evidence that instruction-based advice may not change fixed-pie perceptions comes from a study by Van Boven and Thompson (2003). They compared the mental models and trade-off insights reported by students with no prior expertise after engaging in three different tasks. In the standard negotiation condition, two students played the role of brokers and conducted a commodity negotiation that had integrative potential-one party could profit more from trading rice and the other party could profit more from trading wheat. In the didactic training condition, participants read the same negotiation instructions, but instead of actually negotiating, they were given advice about negotiating. This advice consisted of a written analysis of how both parties could reach the maximum joint gain. Finally, participants in the experiential training condition began the negotiation like participants in the standard negotiation condition, but were interrupted after five minutes. At that point, they received the same advice as in the didactic training condition, and discussed this with their opponent. The researchers assessed all participants' trade-off insights by asking what their perceptions of their opponents' payoffs were. Participants also rated the relatedness of all combinations of 15 terms related to the negotiation (e.g. rice, wheat, exchange information, compromise, etc.). These relatedness judgments were used to compute graphical representations of the participants' mental models. Participants in the didactic training condition (advice only) showed the fewest trade-off insights and had mental models similar to those of participants who negotiated, but failed to reach integrative agreements. So although advice alone did not help to develop trade-off insights, participants in the experiential training condition who gained negotiation experience before receiving advice (experience and advice) developed the best trade-off insights of all and had mental models similar to those of participants who fully realized the integrative potential of the negotiation. That is, advice led to more accurate perceptions when preceded by a real negotiation experience. We will come back to this finding when discussing the combined effects of experience and advice.

\section{Effects of experience}

These and other studies suggest that advice may be insufficient to improve negotiation skills. Few people would agree that people become good negotiators simply by reading negotiation textbooks. Yet many people would agree that 'practice makes perfect' where negotiation skills are concerned. Skilled negotiators often have an extensive track record, and it seems unlikely that 
negotiation skills are innate. Several experiments have investigated the development of outcomes that non-expert negotiators achieve in successive negotiations with integrative potential. In some studies, joint outcomes improved both over negotiation rounds and within negotiators (Thompson, 1990a, 1990b, 1991). Thompson and DeHarpport (1994), however, found no effects of experience when negotiators engaged in different tasks over time. They only observed an effect of experience when negotiators were provided with feedback on their performance after each round. All in all, there is thus mixed support for 'learning by doing' when it comes to negotiation.

Research in cognitive and educational psychology has shown that people recall superficial similarities more easily than structural ones. This led Gentner, Loewenstein, and Thompson (2003) to conclude that 'our ability to take advantage of our prior experiences is limited' (p. 93). During repeated negotiations, people could discover either superficial or structural similarities among the negotiations. Negotiation experience that is based on the discovery of superficial similarities (e.g. the kind of goods that are traded) is of little use for becoming a better negotiator. To achieve that goal, people must learn negotiation principles, such as the use of integrative potential through the formation of contingency contracts or through logrolling (the mutually beneficial exchange of concessions on issues of different priorities). To learn these principles, Gentner and her colleagues argued, people must discover structural rather than superficial similarities between negotiations. Gaining such expertise is seldom accomplished by simply negotiating repeatedly.

\section{Experience and advice in negotiation}

Several studies indicate that expertise in negotiation is best achieved through experience and advice. Gentner et al. (2003), for example, demonstrated the effectiveness of negotiation training based on analogical encoding in a series of experiments. In their research, novice bargainers had to read two cases describing successful negotiations. In a guided-analogy training condition, participants were advised to compare these two cases and find the underlying structure common to both cases (which was either the implementation of a contingency contract or the discovery of mutually beneficial trade-offs). In other conditions, participants read the cases separately or received no training at all. The results showed that when participants found the underlying principle through analogical encoding, they could transfer it to a subsequent negotiation. Guided-analogy training in combination with some kind of experience (reading about two negotiation cases) therefore increased subsequent negotiation performance.

Similar evidence for the benefits of experience and training was found by Nadler, Thompson and Van Boven (2003). In a study of different types of learning, dyads negotiated an employment contract and their outcomes were assessed. Then they received either analogical training (two short vignettes describing negotiations in which trade-offs were made), or engaged in observational training (watching a videotape of a negotiation like the one they had just finished, in which the bargainers reached a fully integrative agreement). A control group received no training at all. Afterwards, the same dyads engaged in a second, different negotiation. Nadler et al. found no significant improvement in the control group. This suggests that experience alone may be insufficient to improve negotiation performance. Performance was improved, however, for dyads that received observational or analogical training between the two negotiations. They reached higher joint outcomes and made more profitable trade-offs in the second negotiation than did dyads that received no such training.

Finally, the research by Van Boven and Thompson (2003) described earlier also demonstrated the benefits of a combination of experience and training. Remember that in that research, advice did not help negotiators to develop trade-off insights, unless the negotiators had gained some experience before they received the advice.

There are at least two reasons why combining experience and advice might improve negotiation performance beyond the benefits of either advice or experience alone. First, bargainers 
can compare the advice they receive with their own experience from earlier negotiations. This would help them to transfer the advice and adjust their negotiation behavior, which in turn should improve their performance. Second, people (especially those with little negotiation experience) tend to view negotiations as a game that one either wins or loses. This results in fixed-pie perceptions and a generally competitive approach, which makes integrative agreements unlikely (De Dreu \& Carnevale, 2003). But after experiencing a negotiation, negotiators should be more motivated to follow advice. Accordingly, we predict that a combination of experience and advice leads to better negotiation outcomes than experience or advice alone (Hypothesis 1).

As mentioned earlier, research on negotiation experience has focused on the outcomes of negotiations, rather than on negotiation behaviors. As a result, we know little about the underlying processes that might account for the effects of experience (and advice). A second goal of our research was thus to explore the behavioral processes triggered by experience and advice that might lead to improved negotiation. Negotiation research (e.g. Ben-Yoav \& Pruitt, 1984; Kimmel, Pruitt, Magenau, \& Carnevale, 1980) has demonstrated that joint outcomes are related to three types of negotiation tactics: distributive behavior, information exchange, and heuristic trial and error. The aim of distributive behavior is to force opponents to make concessions. This usually leads to poorer joint outcomes (Pruitt \& Lewis, 1975). Information exchange and heuristic trial and error are strategies that help people to identify mutually satisfying settlements. Both strategies have been shown to increase the likelihood of reaching integrative agreements and high joint outcomes (De Dreu, Weingart et al., 2000). Past research on experience (and advice) in negotiation has not revealed whether their effects on joint outcomes are due to: (a) less distributive behavior; (b) more information exchange; (c) more heuristic trial and error; or (d) any combination of these tactics. We hope to resolve this issue.

Non-expert negotiators seldom engage in information exchange, displaying lots of distributive behavior and heuristic trial and error instead
(Carnevale, Pruitt, \& Seilheimer, 1981; Pruitt \& Lewis, 1975). Weingart et al. (1996) found that showing such negotiators descriptions of integrative as well as distributive tactics increased the tendency to exchange information, but did not affect distributive behavior. This suggests that contentious (distributive) behavior is the 'default' option at first, and that learning (through experience and/or advice) helps negotiators to engage in problem solving behavior (heuristic trial and error or information exchange). Accordingly, we predicted that the combination of experience and advice would lead negotiators to engage in more problem solving (Hypothesis 2). As additional research questions, we explored whether negotiators engage in less contentious behavior as they gain experience, and whether they make more accurate judgments about each other's interests.

\section{Method}

\section{Participants and experimental design}

Participants were 140 students (aged between 18 and 35 years, $M d=22$ ) from the FriedrichAlexander University in Erlangen. They were asked to sign up for a project in which people's negotiation behavior would be audiotaped and analyzed by a psychology undergraduate student, but they were given no further details about the research. As an incentive, cash prizes (three prizes of DM100, and two prizes of DM50, approximately US $\$ 50$ and US $\$ 25$, respectively) for the five best-performing participants were promised. Two students of the same sex were scheduled for each session. Dyads were randomly assigned to one of three experimental conditions (experience and advice vs. advice only vs. experience only). Two dyads did not complete the experiment and so their data were not included in the analyses, leaving a sample of 34 female and 34 male dyads.

\section{Materials}

Two negotiation tasks were used in random order. One concerned a negotiation between union and management representatives, who were required to reach agreement on four issues-salary, medical coverage, starting date, and contract 
duration. The other task concerned the sale of an old building. In this task, agreement had to be reached about the price, renovation, monthly rate of payment, and moving in date. Table 1, which displays the payoff schedules used in both negotiations, shows that priorities among these issues differed. For example, in the union-management negotiation, the full integrative potential was realized by settling on a high salary (Level 5 on Issue 1) and low medical coverage (Level 1 on Issue 3). In both tasks, fully integrative agreements provided both parties with 4000 points, whereas a 50-50 compromise yielded only 2800 points (for a full discussion, see Thompson, 1991). The payoff schedules in the two negotiations differed with respect to the position (first or third column) of the highest priority issue. This ensured that the payoff schedule participants received in the second round was not identical to the one from the first round.

The advice consisted of three tips, labeled 'The Three Golden Hints for Successful Negotiation'. These were:

(1) Don't see the negotiation as "What the other person gets is what I lose", but try to reach the best outcome for both of you; (2) Ask your partner which item is most important to him or her; (3) Inform your partner which item is most important to you.

Depending on the experimental condition, participants received a sheet of paper that contained these tips either before or after their first negotiation (in the advice-only or experience-and-advice conditions, respectively, see below). To make sure that participants read the advice carefully, they were asked whether they considered the hints useful (coded as 0 not useful at all; 3 very useful) and whether they intended to act on them ( 0 no intention; 3 strong intention).

\section{Procedure and dependent measures}

Upon arriving at the laboratory, the members of each dyad were seated at a table opposite each other. Participants were randomly assigned the roles of buyer and seller, or union and management, respectively. They received a lottery ticket as an award for participation, some written negotiation instructions, and a payoff schedule. Participants knew their own points, but were not informed about the points of their opponent. They were instructed to

Table 1. Payoff schedules

\begin{tabular}{|c|c|c|c|}
\hline Issue 1 & Issue 2 & Issue 3 & Issue 4 \\
\hline \multicolumn{4}{|c|}{ Payoff schedule for Party A } \\
\hline Level 1 (1600) & Level $1(0)$ & Level 1 (4000) & Level $1(2400)$ \\
\hline Level 2 (1200) & Level $2(-600)$ & Level 2 (3000) & Level 2 (1800) \\
\hline Level 3 (800) & Level $3(-1200)$ & Level 3 (2000) & Level $3(1200)$ \\
\hline Level 4 (400) & Level $4(-1800)$ & Level 4 (1000) & Level 4 (600) \\
\hline Level $5(0)$ & Level $5(-2400)$ & Level $5(0)$ & Level $5(0)$ \\
\hline \multicolumn{4}{|c|}{ Payoff schedule for Party B } \\
\hline Level $1(0)$ & Level $1(-2400)$ & Level $1(0)$ & Level $1(0)$ \\
\hline Level 2 (1000) & Level $2(-1800)$ & Level 2 (400) & Level 2 (600) \\
\hline Level 3 (2000) & Level $3(-1200)$ & Level $3(800)$ & Level 3 (1200) \\
\hline Level 4 (3000) & Level $4(-600)$ & Level 4 (1200) & Level $4(1800)$ \\
\hline Level $5(4000)$ & Level $5(0)$ & Level 5 (1600) & Level $5(2400)$ \\
\hline
\end{tabular}

Note: Instead of Party A, Party B, and Issues 1 to 4, the following labels were used: Management, labor union, salary, starting date, medical coverage, and duration in the collective bargaining task, and seller, buyer, price, renovation, monthly rate, and moving in date in the castle sale task, respectively. The five levels within each issue either had labels with high face value, such as 10\%, 20\%, 30\%, 40\%, 50\%, 1 month, 2 months, 3 months, etc., or abstract labels such as $A, B, C, D, E$. Participants were assigned the role of Party A in one negotiation and of Party B in the other. They were told that the numbers in parentheses were the points they would earn. Each task contained two purely distributive issues ( 2 and 4 ) and two issues that could be logrolled to maximize joint outcome (1 and 3 ). 
reach an agreement on all four issues within 15 minutes. The experimenter announced when 14 minutes had passed. ${ }^{1}$ Communication was unrestricted, except that participants could not physically exchange their payoff schedules. All participants agreed to have their negotiations tape-recorded.

Dyads in the experience-only condition negotiated twice. As an unrelated filler task, inbetween those negotiations, participants received four matrices containing the numbers from 1 to 90 and were asked to draw a line starting by the number 1 and connecting as many numbers as possible within 30 seconds. This task was selected because it was easy to administer and kept participants busy for about the same amount of time that participants in the experience-and-advice conditions spent on their advice instructions. Dyads in the advice-only condition received the advice prior to their first (and only) negotiation. Dyads in the experienceand-advice condition received the advice after completing their first negotiation, and then they engaged in a second negotiation.

After every negotiation, participants wrote down the agreement on their payoff schedules, but did not discuss with their opponents the number of points they had earned. ${ }^{2}$ After their last negotiation, participants completed a questionnaire assessing their perceptions of their opponents' preferences (see below). As in previous research (e.g. Thompson, 1990b, 1991), participants were shown a payoff schedule that displayed blanks instead of points. Then they were asked to put numbers into the blanks to indicate what they thought their counterpart's payoff schedule looked like. Participants further provided some demographic data. Finally, they were thanked for their participation. Once they were debriefed, participants were told that because different experimental conditions could lead to different performances, everyone would actually have an equal chance to win a prize. About three weeks after the experiment, five winners were randomly selected and awarded a prize.

Joint outcome was calculated by adding the points that both dyad members earned on all four issues in one negotiation. The lowest possible score was 3,200 . The more negotiators integrated their interests, the closer their score came to 8,000 .

Duration was the time negotiators needed to reach agreement; impasses were assigned a duration of 15 minutes.

Negotiation behavior was assessed from the transcriptions of the tape recordings. Speaking turns were categorized using a coding system used by several other researchers (e.g. De Dreu, Giebels, \& Van de Vliert, 1998; Harinck, De Dreu, \& Van Vianen, 2000; Pruitt \& Lewis, 1975). The codes we used are listed in Table 2. Each speaking turn was assigned one or more codes, depending on the content of the speaking unit. Each code could be assigned only one time to each speaking unit. If, for example, one negotiator asked for an offer and uttered two warnings, before the other negotiator interrupted, then the speaking term would get one code for asking for an offer and one code for threat or warning. Two raters independently coded 29 randomly chosen negotiations (one out of four). An overall agreement of $88.0 \%$ showed that the coding reliability was high. ${ }^{3}$ Disagreements were resolved through discussion between the coders. Only one person coded the remaining 87 negotiations. Because later analyses were performed at the dyadic level, we counted the frequency of each code for each negotiation (rather than for each negotiator). To control for the different lengths of the negotiations (between 5 and 57 speaking turns), we calculated relative frequencies for each code by dividing its absolute frequency by the number of speaking turns. We then logit transformed these relative frequency scores to normalize their distributions (Cohen, Cohen, West, \& Aiken, 2003). Analyses with non-transformed scores yielded the same results.

We submitted the logit transformed frequency scores for the negotiation behaviors to an exploratory principal component analysis (with varimax rotation) to investigate whether broader negotiation strategies might have produced the specific negotiation behaviors. We found two strong factors, with eigenvalues of 4.97 and 2.76, that seemed to reflect traditional descriptions of negotiation behavior (e.g. Lewicki, Barry, Saunders, \& Minton, 2003). ${ }^{4}$ The first factor 
Table 2. Coding system

Codes assigned per speaking unit

Information exchange

1. Asking the other for an offer or a suggestion or a reaction to an offer

2. Inquiring about the other's points or priorities

3. Providing information (about points or interests)

4. Asking for or providing explanation (about behavior)

Persuasive arguments

5. Arguments referring to role instruction or context

6. Downward comparisons

7. Threats and warnings

8. Commitment to a certain position

Offers

9. Offering an exchange

10. Proposing a common or specific offer

11. Repeating an offer

12. Accepting an offer

13. Rejecting an offer

Other remarks

14. Insight into and understanding of the other's priorities

15. Cooperative statements

16. Derogations and impolite statements

17. Humor and friendly jokes

18. Social remarks

19. Remarks or suggestions on the process

20. Common remarks or questions about the role

was labeled 'contentious behaviors', because the following behaviors loaded strongly $(>.40)$ on that factor: rejecting an offer, repeating an offer, commitment to a certain position, persuasive arguments, unfriendly remarks, and threats and warnings. All of these are traditionally associated with distributive bargaining (Lewicki et al., 2003). We calculated a composite contending score $(\alpha=.75)$ by averaging the logit transformed frequencies for these behaviors and multiplying the result by 100 . The second factor was labeled 'problem solving behavior', because the following behaviors loaded strongly (>.40) on it: making cooperative statements, inquiring about the other's points or priorities, providing information about one's own points or priorities, and showing insight into, and understanding of the other's priorities. All of these are traditionally associated with integrative bargaining
(Lewicki et al., 2003). We calculated a composite problem solving score $(\alpha=.76)$ by averaging the logit transformed frequencies for these behaviors and multiplying the result by 100 .

We used the participants' perceptions of their opponents' payoff schedules to calculate judgmental accuracy scores. These scores were based on the deviations between negotiator's estimates and the true values for the two logrolling issues. They were transformed to range between 0 (fixed-pie perception) and 1 (perfect accuracy). Imagine, for example, that a buyer in the castle negotiation estimated that the seller would earn 3600 points more on price Level 1 than on price Level 5. Furthermore, this buyer estimated that for the monthly rate, the seller could earn 2000 points more on Level 1 than on Level 5. This hypothetical buyer had a correct understanding of the opposed interests within each issue-remember that the buyer earned more on Level 5 than on Level 1. Yet, this buyer had a pretty strong fixed-pie bias, reflecting little understanding of the different priorities between parties. The buyer assumed that his or her most valuable issue, price, was very important to the seller as well. Yet this assumption was inaccurate-remember that for the buyer there were 4000 points at stake on the issue of price. For the seller, the stakes on the issue of price were actually much lower, namely 1600 points. Similarly, the buyer in this example underestimated the true importance of monthly rate to the seller. The buyer would have earned an accuracy score of $[(4000-3600) /(4000-$ $1600)+(1600-2000) /(1600-4000)] / 2=0.33$. Accuracy indices were not computed for 12 participants who filled in the blanks as if both negotiators would earn the most points on the same level. Accuracy scores were significantly correlated within dyads (intraclass correlation of $r=.31, p<.05)$. Even though averaging accuracy scores within dyads produced similar results in later analyses, we chose to assign each dyad the score of its most accurate member. Our rationale for this was that discovering integrative potential in a negotiation is a disjunctive task. One negotiator with an accurate understanding of the situation is enough to produce benefits for both persons. 


\section{Results}

\section{Treatment of the data}

Data within dyads were dependent and negotiator role did not interact with any of the dependent measures. Hence we collapsed over role and used the dyad as the unit of analysis. Dyad gender had no significant main or interaction effects (all $p s>.10$ ), so it is not reported in the subsequent analyses. One dyad in the advice-only condition, two dyads in the experience-only condition, and three dyads in the experienceand-advice condition did not reach agreement in the first negotiation. Impasse was not related to condition $\left(\chi^{2}(2, N=68)=0.77, n s\right)$. The only dyad that did not reach agreement in the second negotiation was in the experience-only condition. Impasse dyads create a problem for data analysis: assigning impasse a score of zero for negotiation outcome would lead to artificially high variance. As recommended by Lewis and Fry (1977), we assigned impasse dyads the lowest joint outcome reached by an agreement dyad, namely 4400 points. (Removing impasse dyads from the analysis or assigning them the score of 5600 points would have led to the same pattern of results.) To test our hypotheses, we made a comparison between the first (i.e. the only) negotiation in the advice-only condition, the second negotiation in the experience-only condition, and the second negotiation in the experience-and-advice condition.

\section{Reception of and compliance with the advice}

Participants rated the tips as useful, no matter whether they received them prior to their first negotiation or prior to their second negotiation $(M=2.20, S D=0.76$ and $M=2.25, S D=0.64$, respectively; $t(86)=.34, n s)$. In both groups, mean usefulness ratings were higher than the scale midpoint of $1.5(t(39)=5.82$, and $t(47)=8.17$, $p s<.001)$. Participants who received the tips prior to their second negotiation indicated a marginally stronger intention to apply them than did participants who received them prior to their first negotiation $(M=1.75, S D=0.89$ vs. $M=1.40, S D=0.74 ; t(86)=1.98, p=.051)$. (To assess whether participants perceived the advice, we compared these individual ratings at the individual, not the dyadic level. This was possible because the ratings were made before the dyadic interactions and thus were not dependent within dyads. Averaging the ratings within dyads, however, led to the same conclusions.)

We also investigated whether dyads followed the advice to exchange information. In the first round of negotiation, 18 out of the 20 dyads $(90.0 \%)$ in the advice-only condition requested or gave information in at least one speaking turn. This is significantly more frequent than in the other two conditions, where dyads received no advice before their first negotiation. Only 11 out of $24(45.8 \%)$ and 12 out of $24(50.0 \%)$ dyads in the experienceonly and the experience-and-advice conditions (respectively) exchanged any information at all $\left(\chi^{2}(2, N=68)=10.53, p<.01\right)$. In the second round, 23 out of 24 dyads $(95.8 \%)$ in the experience-and-advice condition exchanged information, which is significantly more frequent than the 16 out of 24 dyads $(66.7 \%)$ that did so in the experience-only condition $\left(\chi^{2}(1, N=48)=\right.$ $6.70, p<.01)$. Obviously, almost all of the dyads that received advice engaged in at least some information exchange, whereas significantly fewer of the dyads that did not receive advice did so. It thus seems safe to conclude that participants read and understood the advice. ${ }^{5}$

\section{Correlations among dependent variables}

Table 3 shows the correlations among the main dependent variables. The correlation between joint outcome and duration was highly negative, indicating that dyads reaching more profitable agreements needed less time to negotiate. The correlations also showed that higher joint outcomes were related to more problem solving, less use of contentious tactics, and more accurate judgments of the negotiation situation. Not surprisingly, judgmental accuracy was positively correlated with problem solving-dyads that used problem solving tactics (including information exchange) had more accurate judgments about each other's preferences. And judgmental accuracy was highly negatively correlated with contending. The use of such tactics as threats, 
Table 3. Means, standard deviations, and correlations among the main dependent variables

\begin{tabular}{|c|c|c|c|c|c|c|}
\hline & $M$ & $S D$ & 1 & 2 & 3 & 4 \\
\hline 1. Joint outcome & 6809 & 997 & - & & & \\
\hline 2. Duration & 8.38 & 4.23 & $-.58 * * *$ & - & & \\
\hline 3. Contending & 4.09 & 3.30 & $-.55^{* * *}$ & $.65^{* * * *}$ & - & \\
\hline 4. Problem solving & 3.84 & 4.04 & $.47 * * *$ & $-.60 * * *$ & $-.61 * * *$ & - \\
\hline 5. Judgmental accuracy & 0.58 & 0.43 & $.51 * * *$ & $-.36 * *$ & $-.49 * * *$ & $.43 * * *$ \\
\hline
\end{tabular}

$* * * p<.001 ; * * p<.01$ (two-tailed).

Notes: $N=68$ dyads. All variables refer to the last negotiation, i.e. to the second negotiation of dyads who negotiated twice, and to the first negotiation of dyads who negotiated once. All coefficients are Pearson correlation coefficients.

warnings, or positional statements was associated with less accurate perceptions of the bargaining situation.

\section{Effects of advice or experience}

Table 4 gives the mean joint outcomes achieved in all rounds of the negotiation. A one-way analysis of variance (ANOVA) revealed that joint outcomes in the first negotiation were not influenced by condition $(F(2,65)<1$, ns, $\left.\eta^{2}=.025\right)$. The 'baseline' performance of the experience-only dyads and the experienceand-advice dyads was about the same as the performance of dyads that received advice prior to their first negotiation. This finding suggests that advice by itself was not enough to improve negotiation performance.
We also examined whether dyads that negotiated twice achieved higher joint outcomes in the second negotiation. The joint outcomes of the experience-only and the experience-andadvice dyads were entered in an ANOVA with condition and negotiation task as betweendyads factors and round as a within-dyads factor. A significant main effect of round $(F(1$, $\left.44)=14.54, p<.001, \eta^{2}=.248\right)$ revealed higher joint outcomes in the second negotiation. This effect was qualified by a marginally significant interaction between round and condition $\left(F(1,44)=3.37, p<.10, \eta^{2}=.071\right)$. Paired-sample $t$ tests revealed that experience-and-advice dyads improved their joint outcomes significantly over rounds $(t(23)=5.36, p<.001)$, whereas experience-only dyads did not $(t(23)=1.19, n s)$.

Table 4. Main outcome and process measures depending on experimental condition

\begin{tabular}{|c|c|c|c|}
\hline & $\begin{array}{l}\text { Experience-only } \\
\quad(n=24)\end{array}$ & $\begin{array}{l}\text { Advice-only } \\
\quad(n=20)\end{array}$ & $\begin{array}{l}\text { Experience and advice } \\
\qquad(n=24)\end{array}$ \\
\hline \multicolumn{4}{|l|}{ First negotiation } \\
\hline Joint outcome & $6200_{\mathrm{a}}(1133)$ & $6590_{\mathrm{a}}(979)$ & $6250_{\mathrm{a}}(1104)$ \\
\hline Duration & $10.67_{\mathrm{a}}(3.34)$ & $10.30_{\mathrm{a}}(3.51)$ & $10.75_{\mathrm{a}}(3.84)$ \\
\hline Contending & $5.96_{\mathrm{a}}(2.31)$ & $4.54_{\mathrm{a}}(2.70)$ & $4.93_{\mathrm{a}}(3.19)$ \\
\hline Problem solving & $1.63_{\mathrm{a}}(3.08)$ & $3.31_{\mathrm{a}}(3.28)$ & $2.13_{\mathrm{a}}(3.14)$ \\
\hline \multicolumn{4}{|l|}{ Last negotiation } \\
\hline Joint outcome & $6550 \mathrm{a}(1118)$ & 6590 a $(979)$ & $7250_{\mathrm{b}}(735)$ \\
\hline Duration & $9.46_{\mathrm{a}}(3.81)$ & $10.30_{\mathrm{a}}(3.51)$ & $5.71_{b}(3.93)$ \\
\hline Contending & $5.72_{a}(3.80)$ & $4.54_{a}(2.70)$ & $2.07_{\mathrm{b}}(2.00)$ \\
\hline Problem solving & $1.63_{\mathrm{a}}(3.08)$ & $3.31_{a}(3.28)$ & $6.48_{\mathrm{b}}(4.08)$ \\
\hline Judgmental accuracy & $0.43_{\mathrm{a}}(0.41)$ & $0.54_{\mathrm{ab}}(0.41)$ & $0.76_{\mathrm{b}}(0.42)$ \\
\hline
\end{tabular}

Notes: $n$ refers to the number of dyads per condition. Numbers in parentheses are standard deviations. In the advice-only condition, 'first negotiation' and 'last negotiation' refer to the same (i.e. the only) negotiation. Means not sharing the same subscript within a row differ at $p<.05$ according to a Duncan test. 
This finding suggests that experience by itself may not be enough to improve negotiation performance.

\section{Effects of experience and advice}

Next, the five dependent variables (all referring to the last negotiation) were submitted to 3 (condition) $\times 2$ (task) ANOVAs. Means and standard deviations for the variables broken down by experimental condition are displayed in Table 4.

As predicted in Hypothesis 1, condition had the main effect on joint outcome $(F(2,62)=3.91$, $\left.p<.05, \eta^{2}=.112\right)$. A Duncan test $(p<.05)$ showed that experience-and-advice dyads achieved a higher joint outcome than did dyads in the other two conditions, which did not differ significantly from each other. There was no task main effect, nor any task by condition interaction effect. Condition also influenced negotiation duration $\left(F(2,62)=10.48, p<.001, \eta^{2}=.253\right)$. A Duncan test $(p<.05)$ showed that dyads in the experience-and-advice condition reached agreement faster than did dyads in the other two conditions, which did not differ significantly from each other. ${ }^{6}$ Taken altogether, the results so far were in line with our expectation that advice combined with experience would improve negotiation performance.

In Hypothesis 2, we predicted that negotiators would engage in more problem solving in a second (as compared to a first) negotiation, but only when they were given advice and cues about the task. ANOVA revealed the predicted main effect of condition on problem solving $\left(F(2,62)=12.22, p<.001, \eta^{2}=.283\right)$. A Duncan test $(p<.05)$ showed that experience-and-advice dyads engaged in more problem solving than did advice-only and experience-only dyads, which did not differ from each other in this regard. Results further revealed a significant main effect of condition on judgmental accuracy $\left(F(2,62)=3.91, p<.05, \eta^{2}=.112\right)$. Duncan's test $(p<.05)$ indicated that dyads in the experienceand-advice condition had more accurate perceptions of each other's interests than did dyads in the experience-only condition. Dyads in the advice-only condition were in-between and did not differ from the other two conditions on this measure. There was no task main effect, nor any task by condition interaction effect. Finally, with regard to contending, the only significant effect was a main effect of condition $(F(2,62)=9.66$, $\left.p<.001, \eta^{2}=.238\right)$. A Duncan test $(p<.05)$ showed that dyads in the experience-and-advice condition used less contentious tactics than did dyads in the other two conditions, which did not differ significantly from each other.

The negotiation behaviors displayed by dyads in the three conditions are illustrated in Figure 1, with solid bars representing contending, open bars representing problem solving behaviors, and error bars representing standard errors. The figure shows that: (a) experience-only dyads did not change their behavior from the first to the second round of negotiation (pairedsample $t$ tests comparing behaviors across rounds of the negotiation did not indicate significant differences for either contending $t(23)=$ -0.42 , ns or problem solving $t(23)=0.48, n s)$; (b) experience-and-advice dyads did change their behavior across rounds (less contending $t(23)=-5.45, p<.001$; more problem solving, $t(23)=6.67, p<.001)$; (c) advice did not significantly reduce contentious behavior, in that advice-only dyads engaged in as much contending as the two unadvised groups during the first round $(t(66)=-1.74, p=.09)$; and (d) advice led to slightly more problem solving, in that the difference in problem solving between the advice-only condition and the other two conditions during the first round of negotiations was marginally significant $(t(62.72)=1.86$, $p=.07)$.

\section{Mediation analysis}

To assess whether problem solving, contending, or judgmental accuracy mediated the influence of the experimental manipulations on joint outcome, we performed three sets of regression analyses as proposed by Cohen et al. (2003). The first analysis in each set was always the same-we regressed the dependent variable (joint outcomes) on the independent variable (experimental condition). The three levels of experimental condition were coded into two dummy variables. Dummy 1 was assigned a value of 1 for the experience-and-advice condition 


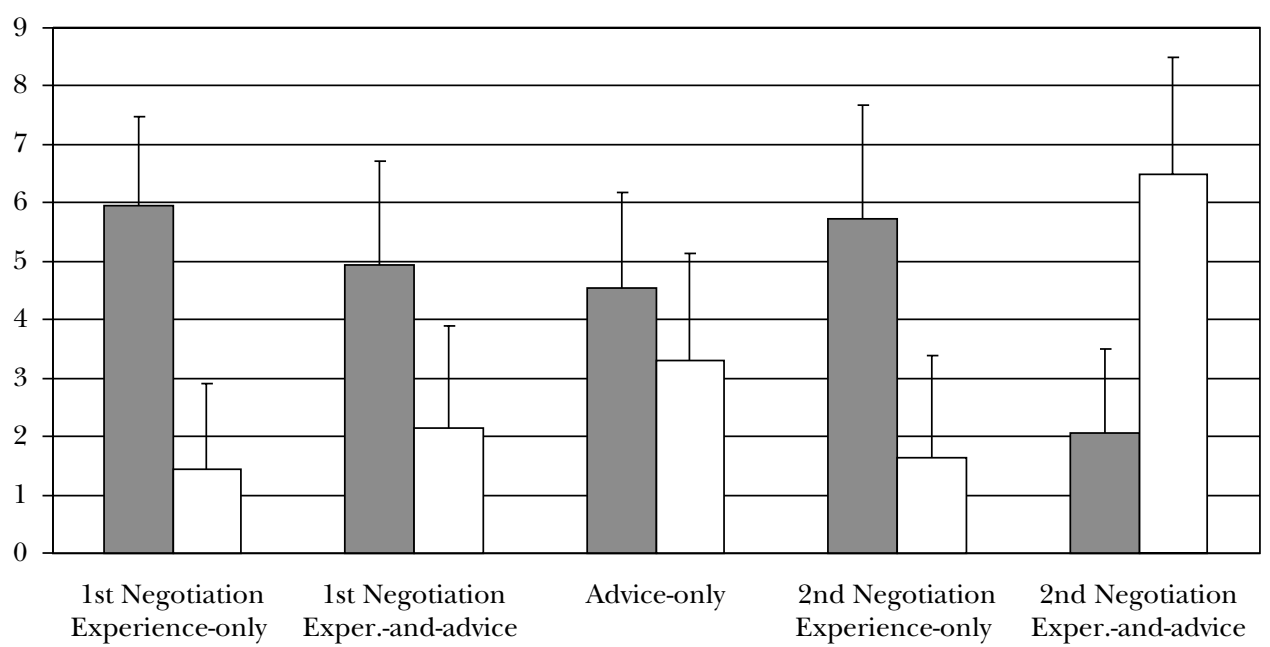

Figure 1. Negotiation strategies $(+S E)$ depending on negotiation round and experimental condition. Solid bars represent contending, open bars represent problem solving.

and 0 for the other two conditions. Dummy 2 was assigned a value of 1 for the experience-only condition and 0 for the other two conditions. Dummy 1, but not Dummy 2, proved to be a significant predictor of joint outcomes $(\beta=.32$, $p<.05)$. The second analysis in each set was to regress one of the potential mediators onto the independent variable. Finally, the third analysis in each set was to regress joint outcomes onto one of the mediators and the independent variable, to see if the regression weight for the independent variable became weaker as a result.

In the first set of regression analyses, we investigated whether the effect of condition on joint outcomes was mediated by problem solving behavior. As noted above, the first analysis showed that condition had a significant effect on joint outcomes. The second analysis showed that condition also had a significant effect on the mediator, problem solving behavior $(\beta=.38$, $p<.01)$. Finally, the third analysis showed that when condition and problem solving behavior were both used to predict joint outcome, the mediator had a significant effect on the dependent variable $(\beta=.42, p<.01)$, whereas the initially significant effect of condition became nonsignificant $(\beta=.16, n s)$. A Sobel test revealed that this reduction was statistically significant $(Z=2.17, p<.05)$. These results showed that the effect of condition on joint outcomes was mediated by problem solving behavior.

In the second set of regression analyses, we investigated whether contending mediated the effect of condition on joint outcomes. The first analysis (again) showed that condition had a significant effect on joint outcomes. The second analysis showed that condition also had a significant effect on the mediator, contending behavior $(\beta=-.35, p<.01)$. Finally, the third analysis showed that when condition and contending behavior were both used to predict joint outcomes, the mediator had a significant effect on the dependent variable $(\beta=-.52$, $p<.001)$, whereas the initially significant effect of condition became nonsignificant $(\beta=.13, n s)$. A Sobel test revealed that this reduction was statistically significant $(Z=2.35, p<.02)$. These results show that the effect of condition on joint outcomes was mediated by contending.

In the third set of regression analyses, we investigated whether the effect of condition on joint outcome was mediated by judgmental accuracy. Again, the first analysis showed that condition had a significant effect on joint outcomes. The second analysis showed that condition had a marginally significant effect on judgmental accuracy $(\beta=.25, p=.08)$. Nevertheless, the initially significant effect of condition became 
nonsignificant $(\beta=.20, n s)$, when both condition and judgmental accuracy $(\beta=.46, p<.001)$ were used to predict joint outcomes. A Sobel test revealed that this reduction was marginally significant $(Z=1.65, p<.10)$. These results point to the mediating role of judgmental accuracy. ${ }^{7}$

All in all, these analyses showed that, compared to unadvised dyads with negotiation experience, or to advised but inexperienced dyads, dyads with experience and advice reached higher joint outcomes through the use of more problem solving and less contentious behaviors and through greater insight into each other's preferences.

\section{Discussion}

Our research investigated whether people learn to become better negotiators through experience, through advice, or through a combination of the two. The findings showed that neither advice nor experience alone leads to more integrative negotiation. The combination of the two, however, strongly affected problemsolving behavior, judgmental accuracy, and joint outcomes.

Dyads that simply engaged in two successive negotiations did not reach a significantly higher outcome in the second round. This replicates the findings of Thompson and DeHarpport (1994), who found no increase in joint outcomes over time for a control group of bargainers that negotiated four rounds without receiving feedback, and the findings of Nadler et al. (2003), who concluded that 'simply having experience... is largely ineffective' (p. 537). We went beyond this earlier research, however, by examining the negotiation behavior of participants and found that experience alone did not make dyads behave differently. Experience-only dyads continued to use only contentious strategies, and did not raise their (low) levels of problem solving.

Like experience without advice, advice without experience was not enough to change negotiation behaviors or performance either. In the first negotiation, dyads that were advised to exchange information did not reach a more integrative agreement than dyads that did not receive advice. Most dyads did, in fact, follow the advice to exchange information. Yet this led to only slightly more problem solving behavior, perhaps because few dyads exchanged more than a minimal amount of information. No major shift toward a cooperative, problem solving style of negotiation occurred. The amount of contentious behavior was the same as in the unadvised dyads.

The negotiations of experienced and advised dyads were the most interesting. These dyads settled on more integrative outcomes, because they engaged in more problem solving behavior and avoided contentious behavior. After a disappointing first round of negotiation, these dyads used the advice to overcome fixed-pie perceptions. Advice was thus effective in improving negotiation performance when given to experienced dyads, but not when given to inexperienced dyads.

Why did experienced dyads use the advice to negotiate more cooperatively and reach more integrative agreements, when inexperienced dyads did not? One possible explanation is that advice cannot be comprehended when people have no actual experience with a task. This explanation, however, seems unlikely-the advice we gave was deliberately brief and easy to understand. Furthermore, process data suggests that participants understood the advice. Dyads did exchange information when they were advised to do so.

Another explanation is that people are more motivated to listen to advice after they attempt to perform a task, but fail. This explanation is in line with research by Smith-Jentsch, Jentsch, Payne, and Salas (1996), which suggests that the experience of failure makes people more receptive to new ideas and increases self-analysis, which leads to better retention of skills and thereby facilitates learning. Our measure of the participants' motivation to use the advice we gave them favors a motivational explanation as well, because people who received the advice after the first round of negotiation reported a greater intention to use it than did those who received the advice before the first round of negotiation. However, we assessed participants' motivation with just one item, so the results are tentative rather than conclusive. 
Our motivational explanation does not contradict earlier studies that did find effects of advice (e.g. Kemp \& Smith, 1994; Nadler et al., 2003; Weingart et al., 1996). Those studies used more elaborate advice, some parts of which may have strengthened participants' motivation to use the advice, or which may have been interpreted by participants as a suggestion to equate outcomes.

\section{Limitations}

We used different scenarios to make our participants assume a new role and talk about a new topic in the second negotiation. Furthermore, the payoff schedules differed with respect to the location of the highest priority issue. These variations in the negotiation task guaranteed that bargainers could not simply repeat an agreement that was successful before. Yet the tasks were structurally similar because logrolling was the key to success in both scenarios. This made learning possible-dyads that found out how to make mutually beneficial concessions in the first negotiation could apply this knowledge in the second negotiation. It is beyond the scope of this experiment to determine whether the effects of experience and advice are similar when tasks differ more.

We deliberately chose to explore the single and combined effects of very brief advice and rather minimal experience. Our advice consisted of just three sentences, and experience was operationalized by having dyads engage in just two similar negotiations. Both operationalizations differ from 'real life', where advice sometimes consists of advanced teaching programs and experience encompasses a larger track record. This jeopardizes the external validity of our findings, but our goal was theory testing rather than providing advice to people who train negotiators or conduct negotiations in realworld settings. In principle, however, we see no reason why our findings and the basic principles uncovered in our research should not generalize to real-world settings or be used to inform training efforts. The advice we used stressed two key aspects of integrative negotiation, namely focusing on joint benefits and exchanging priority information. These are key to success in any negotiation with logrolling potential. Our advice might have weaker effects in negotiation situations that involve other ways to improve outcomes (e.g. cost-cutting, bridging, adding issues, or implementing contingency contracts). However, we are still confident that it is the combination of experience and advice that leads to improved negotiation outcomes, because this combination changed the entire pattern of negotiation behavior, rather than just stimulating logrolling behavior.

Experience was operationalized in a simple way as well. Dyads negotiated twice, and in between the two rounds, they either received advice or engaged in a short filler task. We selected a filler task that was content-free (at least compared to the negotiation scenarios), in the hope that it would not interfere with the transfer of knowledge from one negotiation to the other. We cannot exclude the possibility that interference occurred, however.

\section{Implications and recommendations for future research}

Learning from experience might require reflection. The filler task, however, left little time for reflection. Participants might have learned more from their prior experience if they had been given more time. Nevertheless, we do not think that this had much impact on our results-after all, participants in the experienceand-advice condition did not have much time either. Future research might investigate whether experience has differential value depending on the time available for reflection.

Our results involved the immediate effects of advice and experience. Obviously, training could change behavior for a much longer period of time than the training session itself. The longterm effects of experience and advice are thus an important topic for future research.

What would happen if people were given the advice first and then gained experience afterwards? We think that people are more strongly motivated to follow advice after they have gained experience, so a combination of advice and experience (in that order) would be less helpful, unless (of course) the advice were repeated or remembered before the 
second negotiation. However, our experimental design did not include an advice-and-experience condition. This might be worth investigating in future research.

Interestingly, the combination of experience and advice led to negotiation outcomes that were not only better, but also achieved in shorter time. This suggests that contentious tactics, such as pressuring an opponent or haggling, are inefficient, time-consuming activities. Because competitive behavior in our study was related to inaccurate perceptions of the negotiation situation, this finding also corroborates Thompson's (1990) conclusion that biases are associated with inefficient performance. Another explanation could be that the willingness of participants to settle the deal and secure their earnings is increased when their opponents made offers that yield more profit for the participants than a compromise would have yielded. Future research could investigate how the discovery of mutually beneficial agreements motivates bargainers to make a deal quickly.

Both our manipulations may have influenced the negotiators' goal setting. The fact that experience-only dyads were contentious during both negotiations is akin to something reported in an early negotiation experiment. In a classroom study of repeated bargaining behavior, Kelley (1966) found that experience with bargaining increased students' aspirations, which in turn became manifest in higher first offers. Similarly, experience with the task in our experiment may have increased negotiator's aspirations, which led them to engage in contentious behavior, except when they also received advice. The advice we gave them was also directed at influencing participants' goal-setting, because they were told to focus on the best outcome for both negotiators. In a recent meta-analysis, Zetik and Stuhlmacher (2002) showed that goals have more effect on negotiation performance when a negotiator has experience with a task. However, we did not measure the negotiators' goals in the present study. Investigating how training and experience influence negotiation behavior and performance through goal-setting is definitively an endeavor for future research.
In conclusion, this study adds to our knowledge by investigating not only negotiation outcomes, but also the behavioral processes and cognitive determinants related to the effects of experience and advice. We did not set out to explore the underlying motivational aspects of negotiation behavior. We suggested that bargainers use tactical advice only after experiencing a disappointing first negotiation. Future work could address this issue in more detail by exploring the cognitive and motivational processes triggered by experience, advice, and their combination.

Looking at our results from a practical point of view, it is interesting that a very simple piece of advice can be enough to significantly improve negotiation effectiveness and efficiency. Bargainers, however, need some practical experience to be able to profit from such advice. Combined with practical experience, a short training session, which might be easy to implement, could improve negotiators' performance and help them and their organizations move forward.

\section{Notes}

1. In the first round, 56 dyads finished before the last minute was announced and another 6 dyads reached an agreement within the last minute. In the second round, 1 dyad did not finish before the last minute was announced. The other 47 dyads reached agreement in less than 14 minutes. All of this suggests that dyads had sufficient time to reach agreement.

2. Comparing these notes with the audiotapes showed that all participants wrote down the agreement correctly, and computed the correct number of points.

3. We report percentage agreement between the raters instead of Cohen's Kappa, because the codes in our coding system are not mutually exclusive categories. Percentage agreement does not correct for chance agreement. The high agreement on all codes, however, suggests that our coding did not suffer from coincidental agreement. The raters agreed in $81.3 \%$ to $100 \%$ of their codes, depending on the category. This shows that agreement was high in all coded categories.

4. Five more factors had eigenvalues slightly larger than 1.00. However, we will not discuss those 
further, because the scree plot clearly had an elbow at two components, and because the pattern of factor loadings on the remaining five components did not correspond to traditional descriptions of negotiation strategies. These weaker, uninterpretable factors might be a result of the exploratory nature of this principal component analysis, taking into consideration the large number of variables and the small number of observations.

5. More direct evidence of whether the advice was read and understood could have been obtained by asking participants to summarize or explain the advice they were given. We decided not to do so, to prevent dyads from discussing the advice prior to the negotiation, which might have led them to create and commit themselves to new behavioral norms.

6. There was also a main effect of task on negotiation duration $(F(1,56)=5.19, p<.05$, $\left.\eta^{2}=.077\right)$, indicating that participants negotiated longer about the castle sale $(M=9.35 \mathrm{~min}, S D=4.15)$ than about the salary contract $(M=7.41 \mathrm{~min}, S D=4.13)$. Because task had no effect on the other dependent variables, we are confident that our findings are not dependent on which conflict setting participants were given.

7. In a fourth analysis, we investigated the joint influence of all three mediators at once. Joint outcomes were thus regressed onto condition, contending, problem solving, and judgmental accuracy. In this analysis, the effect of condition become nonsignificant $(\beta=.08, n s)$, whereas significant effects emerged for contending $(\beta=-.32, p<.05)$, and judgmental accuracy, $(\beta=.29, p<.05)$. This analysis is exploratory rather than conclusive, because the relative sizes of regression weights in multiple regression depend on several factors, including measurement issues such as reliability. Nevertheless, the results show further evidence that the effects of experience and advice on negotiation outcomes are mediated by both behavioral (contending) and cognitive (judgmental accuracy) factors.

\section{Acknowledgements}

We thank Astrid C. Homan, Bianca Beersma, Fieke Harinck, Gerben A. van Kleef and three anonymous reviewers for their helpful comments and suggestions on earlier versions of this article.

\section{References}

Bazerman, M. H., Curhan, J. R., Moore, D. A., \& Valley, K. L. (2000). Negotiation. Annual Review of Psychology, 51, 279-314.

Bazerman, M. H., \& Neale, M. A. (1983). Heuristics in negotiation: Limitations to effective dispute resolution. In M. H. Bazerman \& R. J. Lewicki (Eds.), Negotiating in organizations (pp. 51-67). Beverly Hills, CA: Sage.

Ben-Yoav, O., \& Pruitt, D. G. (1984). Resistance to yielding and the expectation of cooperative future interaction in negotiation. Journal of Experimental Social Psychology, 20, 323-335.

Berridge, G. R., Keens-Soper, M., \& Otte, T. G. (2001). Diplomatic theory from Machiavelli to Kissinger. Basingstoke, UK: Palgrave.

Carnevale, P. J. D., Pruitt, D. G., \& Seilheimer, S. D. (1981). Looking and competing: Accountability and visual access in integrative bargaining. Journal of Personality and Social Psychology, 40, 111-120.

Cohen, J., Cohen, P., West, S. G., \& Aiken, L. S. (2003). Applied multiple regression/correlation analysis for the behavioral sciences (3rd ed.). Hillsdale, NJ: Erlbaum.

De Dreu, C. K. W., \& Carnevale, P. J. (2003). Motivational bases of information processing and strategy in conflict and negotiation. In M. P. Zanna (Ed.), Advances in experimental social psychology (Vol. 35, pp. 235-291). San Diego, CA: Academic Press.

De Dreu, C. K. W., Giebels, E., \& Van de Vliert, E. (1998). Social motives and trust in integrative negotiation: The disruptive effects of punitive capability. Journal of Applied Psychology, 83, 408-422.

De Dreu, C. K. W., Koole, S., \& Steinel, W. (2000). Unfixing the fixed pie: A motivated information processing approach to integrative negotiation. Journal of Personality and Social Psychology, 79, 975-987.

De Dreu, C. K. W., Weingart, L. R., \& Kwon, S. (2000). Influence of social motives in integrative negotiation: A meta-analytic review and test of two theories. Journal of Personality and Social Psychology, 78, 889-905.

Druckman, D. (1994). Determinants of compromising behavior in negotiation: A meta-analysis. Journal of Conflict Resolution, 38, 507-556.

Fisher, R., \& Ury, W. (1981). Getting to yes: Negotiating agreements without giving in. Boston: Houghton Mifflin. 
Gentner, D., Loewenstein, J., \& Thompson, L. (2003). Learning and transfer: A general role for analogical encoding. Journal of Educational Psychology, 95, 393-405.

Harinck, F., De Dreu, C. K. W., \& Van Vianen, A. E. M. (2000). The impact of conflict issues on fixed-pie perceptions, problem solving, and integrative outcomes in negotiation. Organizational Behavior and Human Decision Processes, 81, 329-358.

Harvey, N., \& Fischer, I. (1997). Taking advice: Accepting help, improving judgment, and sharing responsibility. Organizational Behavior and Human Decision Processes, 70, 117-133.

Harvey, N., Harries, C., \& Fischer, I. (2000). Using advice and assessing its quality. Organizational Behavior and Human Decision Processes, 81, 252-273.

Kelley, H. H. (1966). A classroom study of the dilemmas in interpersonal negotiations. In K. Archibald (Ed.), Strategic interaction and conflict (pp. 49-73). Berkeley, CA: University of California.

Kemp, K. E., \& Smith, W. P. (1994). Information exchange, toughness, and integrative bargaining: The roles of explicit cues and perspective-taking. International Journal of Conflict Management, 5, 5-21.

Kimmel, M. J., Pruitt, D. G., Magenau, J. M., \& Carnevale, P. J. (1980). Effects of trust, aspiration, and gender on negotiation tactics. Journal of Personality and Social Psychology, 38, 9-22.

Lewicki, R. J., Barry, B., Saunders, D. M., \& Minton, J. M. (2003). Essentials of negotiation (3rd ed.). Boston: McGraw-Hill.

Lewis, S. A., \& Fry, W. R. (1977). Effects of visual access and orientation on the discovery of integrative bargaining alternatives. Organizational Behavior and Human Performance, 20, 75-92.

Lim, J. S., \& O’Connor, M. (1995). Judgmental adjustment of initial forecasts: Its effectiveness and biases. Journal of Behavioral Decision Making, 8, 149-168.

Nadler, J., Thompson, L., \& Van Boven, L. (2003). Learning negotiation skills: Four models of knowledge creation and transfer. Management Science, 49, 529-540.

Neale, M. A., \& Bazerman, M. H. (1991). Cognition and rationality in negotiation. New York: Free Press.

Pruitt, D. G. (1981). Negotiation behavior. New York: Academic Press.

Pruitt, D. G., \& Lewis, S. A. (1975). Development of integrative solutions in bilateral negotiation.
Journal of Personality and Social Psychology, 31, 621-633.

Raiffa, H. (1982). The art and science of negotiation. Cambridge, MA: Harvard University Press.

Rubin, J. Z., Pruitt, D. G., \& Kim, S. H. (1994). Social conflict: Escalation, stalemate, and settlement (2nd ed.). New York: McGraw-Hill.

Smith-Jentsch, K. A., Jentsch, F., Payne, S. C., \& Salas, E. (1996). Can pretraining experiences explain individual differences in learning? Journal of Applied Psychology, 81, 110-116.

Sonnentag, S. (1998). Expertise in professional software design: A process study. Journal of Applied Psychology, 83, 703-715.

Thompson, L. (1990a). An examination of naive and experienced negotiators. Journal of Personality and Social Psychology, 59, 82-90.

Thompson, L. (1990b). The influence of experience on negotiation performance. Journal of Experimental and Social Psychology, 26, 528-544.

Thompson, L. (1991). Information exchange in negotiation. Journal of Experimental and Social Psychology, 27, 161-179.

Thompson, L., \& DeHarpport, T. (1994). Social judgment, feedback, and interpersonal learning in negotiation. Organizational Behavior and Human Decision Processes, 58, 327-345.

Thompson, L., \& Hastie, R. (1990). Social perception in negotiation. Organizational Behavior and Human Decision Processes, 47, 98-123.

Ury, W. (1992). Getting past no: Negotiating with difficult people. London: Century Business.

Van Boven, L., \& Thompson, L. (2003). A look into the mind of the negotiator: Mental models in negotiation. Group Processes $\mathcal{E}$ Intergroup Relations, 6, 387-404.

Weingart, L. R., Hyder, E. B., \& Prietula, M. J. (1996). Knowledge matters: The effect of tactical descriptions on negotiation behavior and outcome. Journal of Personality and Social Psychology, 70, 1205-1217.

Yaniv, I. (2004). Receiving other people's advice: Influence and benefit. Organizational Behavior and Human Decision Processes, 93, 1-13.

Yaniv, I., \& Kleinberger, E. (2000). Advice taking in decision making: Egocentric discounting and reputation formation. Organizational Behavior and Human Decision Processes, 83, 260-281.

Zetik, D. C., \& Stuhlmacher, A. F. (2002). Goal setting and negotiation performance: A metaanalysis. Group Processes $\mathcal{E}$ Intergroup Relations, 5, 35-52.

Paper received 18 May 2005; revised version accepted 12 January 2006. 


\section{Biographical notes}

WOLFGANG STEINEL is an assistant professor at Leiden University, The Netherlands. His research interests include decision-making in mixed-motive interaction, with an emphasis on provision and processing of information, and the effects of social motivation, group norms, affect, or social categorization on negotiations between individuals or group representatives.

ANDREA E. ABELE is currently Professor of social psychology at the Friedrich-Alexander University in Erlangen, Germany. Her research interests include research on basic dimensions of social judgment, both with respect to the self and to other people, career psychology with an emphasis on self-regulation as well as career success and life satisfaction, gender research, and negotiation research.

CARSTEN K. W. DE DREU is currently Professor of organizational psychology at the University of Amsterdam, The Netherlands. His research interests include judgment and decision making in strategic settings, with an emphasis on motivational, cognitive, and affective processes underlying behavior in mixed-motive interdependence (e.g. negotiation, conflict, and group decision making), social influence processes in small group settings, and creativity and innovation in groups. 